Martineau, and others. In the present case, it was probably due partly to shock, and partly to the small amount of blood lost by a patient whose condition was so precarious. Hull.

\section{ON CLINICAL THERMOMETRY, AND THE TAKING OF TEMPERATURES.}

By SURGEON-MAJOR BOILEAU, B.A., M.D., \&c., ARMY MEDICAL STAFF.

The "One-minute" Thermometer delusive, and dangerous to use.-Axillary Temperatures $v$. AIouth Temperatures.Time required for a Correct Observation.-The Temperature of the Human Body.

IT is now many years since I became interested in clinical thermometry. My first temperature charts, the result of thousands of observations, appeared in the eighth volume (1866) of the Army Medical Department Reports, and I believe they were the first systematic series of charts published by any medical officer in the public services. But in saying this $I$ am open to correction. Be this as it may, I have, at all events, for some five-and-twenty years been taking temperatures with all sorts of thermometers, and in many different parts of the globe, including the East and the West Indies, the Mediterranean, North America, and at home.

My first reniarks will now be on the so-called "oneminute" thermometer; and concerning this I had almost written two years aro, but decided not to do so, believing the instrument would soon cease to be advertised; but, the advertisements still appearing, I have changed my mind. The instrument is not only more advertised than ever, but we have now offered to the profession a "half-minute" thermometer, and its use is apparently sanctioned by high anthority. In a recent issue of a contemporary, a Berlin correspondent, writing on the health of the German Emperor, says, "The temperature is always taken in the mouth with a "half-minute' thermometer, which was given to Sir Morell Mackenzie by an eminent surgeon during his last visit to England.

All the physicians are now, however, unanimous in their approval of the 'short-time' thermoneter, and it alone is used in the case." The advocates of this thermometer claim that it will register the temperature of the human body in one minute. "To any medical man who has an extensive practice, this is a great desideratum." "By this latest improvement the time required to mark the maximum temperature is reduced to one minute." "This thermometer is guaranteed to take the maximum temperature of patients in one minute." In such terms are its supposed advantages set forth.

Now, a thermometer can only register the temperature of the heat to which it is exposed. It cannot register the maximum temperature of any body until that maximum is reached, and the maximum temperature of the human body, or of the mouth, is not reached until it is covered up or closed for some time, and this time is more than a minutesome would say ten minutes. That the "one-minute" thermometer will register the existing temperature of a body in one minute is true; but the same is true of any other clinical thermometer-even a cornmon bath or garden thermometer will do this. Take a tumbler of warm water, say at $100^{\circ} \mathrm{F}$.; plunge any clinical thermometer into it, and you will find that the temperature of the water is registered in less than a minute, probably in less than half a minute. This necessarily happens on account of the rery low specific heat of mercury and its high conducting power. The " oneminute" thermometer possesses in this respect for clinical purposes no advantage over any other thermoneter, and to suggest that it does is to mislead, and to imagine that it can give the maximum temperature of patients as it is ordinarily obtained is delusive. It is not merely the temperature of a given part of the body that we desire to know-it is the maximum temperature of the part when removed from the cooling influences of the surrounding air, and it takes some time longer than a minute to get this. When a thermometer is first placed in the axilla, that part of the body has been usually more or less exposed to the external air; when the elbow is bronght to the side to exclude as much as possible all external cooling influences, the temperature of the axilla begins to rise, and in five or more minutes it reaches a maximum. How can this maximum (the tenperature required for the purposes of diagnosis and prognosis) be measured by any instrument until it is attained? Yet we are asked to believe that the "one-minute" thermometer will do this; that it will give the temperature of the patient, the temperature which is to guide the physician, in one minute; and the instrument is distinguished for this important practical purpose from all other thermometers. This is altogether wrong; but it is worse than wrong-it is, in its possible consequences, dangerous. As it cannot give the required temperature in one minute, a lower temperature is accepted, and this may be one, two, or more degrees below the proper temperature. A nurse, dresser, or patient using this "one-minute" thermometer gives the temperature recorded by it in one minute to the physician, and what may be the consequence? A temperature of $100^{\circ}$, say, is given in place of $102^{\circ}$, or perhaps, what is worse, a temperature under $99^{\circ}$, when the correct temperature is $101^{\circ}$ or more. The inference may be that the patient is improving or convalescent, when in reality he may be getting worse, perhaps running into danger, and the anxiety and watchfulness which would result from $x$ knowledge of the real state of things is replaced by a false security, created by the mislearling record, and thus the welfare of the patient jeopardised.

When I first saw the advertisements of this "one-minute" thermometer in the Pioneer of India, the thought occurred to me, What new physical property has been discovered in mercury that will enable it to fulfil such a purpose? accordingly sent to Bombay for one, and found, of course, as I had surmised, that it was simply an instrument somewhat more sensitive than the ordinary clinical thermometers, but in no other way possessing unusual qualities, except the disadvantages of much increased fragility and greater cost. This property of increased sensitiveness might be of some use in certain delicate philosophical experiments in which alternating waves of heat and cold had to be measured by seconds, but for clinical purposes it is of no use whatever. Far from being useful, it is likely to be a source of danger.

These thermometers are largely advertised, and, I believe, have an extensive sale, and I know that a power is attributed to them which they do not possess. On one occasion, a few years ago, I gave a lecture and demonstration on these instruments to the officers of the subordinate medical department in a large station hospital in Bengal, and I found that one of the assistant apothecaries doing duty in the hospital was actually in possession of one of them, having lost no time in procuring one on seeing them advertised. This officer had a large number of temperatures to take morning and evening, and he was greatly pleased, as well he might be, that there seemed to be a means of very much curtailing the time necessary for the work. On hearing what I harl to say on the fallacy of observations so taken, he produced it, and I was afterwards informed that the agent took it back. I cannot believe there is any intention to mislead in connexion with the sale of these thermometers; the makers probably believe the instruments can save time, and are therefore superior to all other thermometers. I have been assured over the counter most ingenuously that "it gives the temperature in one minute, the others take three minutes."

All that I have said concerning the fallacy and danger attending observations made by these thermometers in the axilla applies mutatis mutandis to observations made in the mouth, and they apply with double force to the "halfminute" thermometers. If these thermometers are used as any other thermometers are used they of course answer the same purposes, but they are costly and easily broken, and in those that $I$ have seen the index is set with unusual difficulty.

As to the best part of the body from which to take temperatures, I am decidedly in favour of the axilla. I think the only defence that can be urged for taking them in the mouth-and it is but a poor excuse-is that the practice is convenient, and that it saves trouble; and there is no doubt about this. A person, say, is before you; perhaps a woman in walking dress, or a soldier in his great coat. It is far easier to put a thermometer into the mouth than into the axilla with the usual precautions; and this is the only reason I can see for taking sublingual temperatures. The practice has, however, so many disadvantages that such considerations should have no weight. In the first place, is it not most desirable that there should be uniformity in the taking of tempera- 
tures, in order that all should be directly comparable? Is it not desirable that all temperatures should be referred to one standard? It is worse than inconvenient that some observers should make a practice of taking axillary, and others mouth temperatures. They are not comparable withont certain considerations; and, as I believe and hope that the majority of observers agree that the axillary temperature gives as true an index of the blood heat as is needed, it would be well if the practice was universal; but this is perhaps the least that is to be said in its favour. There are the following considerations. When you place a thermometer in a person's mouth, you shut his mouth in more senses than one. Whilst the temperature is being taken the patient must be silent, and it really is sometimes distressing to see the practitioner standing by watching the speechless subject, who is, moreover, often very uncomfortable, for many people cannot breathe at all easily with their mouthis closed. All this is avoided by taking the temperatures in the axilla. A gain, the instrument is more likely to be broken in the mouth than in the axilla. This is the case with children, in cases of delirium, of partial or complete insensibility, certain spasmodic affections, \&c. Last, but by no means least, there is the offensiveness of the practice-lye it even in the idea only. Is it not objectionable to retain in the mouth an instrument that las been in another person's mouth? Most people object to any but their own toothbrush, even to one belonging to a healthy member of their own family; how much stronger must be the objection to keep in the mouth for some minutes an instrument that in all probability has been recently in the mouths of half a dozen more or less diseased persons. Who would knowingly keep in their closed mouth a thermometer that had been in the mouth of a patient suffering from diphtheria, scarlatina, cancer or syphlilis, various forms of ulceration and suppuration, or of dyspepsia with foul breath and loaded tongre, \&c.? It is no justification to say the thermometer is always thoroughly cleansed first; for, as a matter of fact, this very necessary measure of precaution is sometimes neglected. It must be remembered, too, that a clinical thermometer cannot, like other instruments, be placed in hot water for the purpose of cleaning it; and it requires very hot water indeed to destroy the contagium of disease. Nor is it in every house that sufficiently powerful disinfectants are always at hand in which to place the thermometer before use. Even apart from the possible danger of disease transmission, the ideas suggested by the practice are, to sar the least, disagreeable. No such objections apply to taking the temperature in the axilla. A perfectly clean thermometer is at all times desiralule, but, should it not be quite clean, the axilla is a much safer place for it than the mouth.

The allegation that in the mouth a more correct temperature is obtained than in the axilla may or may not be true; it is not of sufficient force to be an argument agrainst axillary temperatures. The temperature of the blood one cannot get; at best we can get only an index to that temperature, and the axillary index is as reliable as the sublingual. The cases in which we cannot take axillary temperatures compared with those in which we cannot or unquestionably ought not to take nouth temperatures are very few indeed. I would not allow any medical student, nurse, or dresser to take sublingual temperatures. I would teach them from the time they first took a clinical thermometer into their hands that the axilla is the proper place to take all temperatures. Uniformity of observations and safety would thus be secured. If some take temperatures in the mouth, some in the axilla, and some elsewhere - some for one minute, others for five, and others for ten,-it is hopeless to expect that we shall ever have standard charts of reference, to say nothing of the evil consequences of misinterpretations. It is a matter of surprise to me that so many practitioner's still take mouth temperatures, and still more surprising is it to hear them depreciating the value of observations made in the axilla.

Vith regard to the precautions to be attended to in taking axillary temperatures, I will only refer to the one which concerns the time necessary to get an observation that may be relied on for medical purposes. From a very large number of observations that I have made and graphically traced I hold that five minutes are sufficient for every practical purpose, and that it is waste of time to occupy a longer period in an observation. It can be easily proved. Take an ordinary tempernture chart, and let each vertical space represent an interval of fifteen seconds. Let an assistant place any clinical thermometer in the axilla of a patient with some feverish affection, and closely watching the rising mercury call out its height every fifteen seconds from the monent of commencing the experiment. Let this be continued for ten minutes. If a graphic representation of the numbers so obtained be now made on the chart, a paraboloid curve will be projected. Obtain several of these under various circumstances, and if an inspection of the whole will not convince an unprejudiced observer that, for all practical purposes of diagnosis and prognosis, a carefully made observation of five minutes is sufficient, nothing will persuade him.

Although the remarks which I have made above on the fallacy attending conclusions drawn from the "one-minute" thermometer are true, it is also true that reliable temperatures may be taken by the application of a thermometer to the axilla for only one minute. A knowledge of this fact will sometimes be of use in saving the time of those who have cliarge of many patients. It is, for instance, possible to take with one thermometer the temperature of a dozen patients in about twenty minutes, whilst ordinarily it would take over an lour. 'To do so, the patients should be told (under such circumstances as admit of this method of procedure, and with or without the aid of assistants) to bring their elbows to their sides, and place their arms in the usual position. Whilst the medical man is occupied five minutes in taking the temperature of the first patient, the armpits of the remaining patients are, so to speak, heating up and acquiring their maximum temperatures. It will be sufficient then to place the thermometer in the axilla of all but the first for little more than one minute, and thus one can pass from patient to patient, observing correctly the temperature of each in one minute, and it does not require a "short-time" thermometer to do this; any ordinary clinical thermometer will do it. It must be remembered, however, that the thicker the glass of the thermometer the slower it registers. Of course this quick method of taking temperatures must be done with all necessary precautions. They are obvious, and the person who neglects them would neglect a good many other things.

Finally, as to the axillary temperature of the human body in health, my experience goes to prove that it is always under $99^{\circ} \mathrm{F}$. both in the tropics and in cooler regions. Numerous observations made by me in the plains of Bengal fully bear out the conclusions I arrived at fifteen years ago-conclusions which were then published. My observations have now been made in very different climates, under conditions of heat and moisture the most varied; in places where the true shade temperature was very often over $100^{\circ}$; in places where a temperature many degrees below zero was not uncommon; and in places where the hygrometric state of the air, as indicated by the difference between the dry and the wet bulb thermometers, varied from $0^{\circ}$ to $30^{\circ}$. I believe, therefore, I am correct in maintaining that the temperature of man is not higher in the tropics than elsewhere, notwithstanding the belief of those who still accept the teaching of Dr. John Dary. For further information on this subject, I would refer to papers of mine in THE LANCET of Aug. 23rd, 1873, and April 23rd, 1878; also to an important paper in the eighteenth rolume of the Army Medical Department Reports, published in 1878, by Surgeon-Major J. Crosse Johnston; and to communications from Surgeon-General Furnell, of the Madras Army, and others, in THE LANCET of the same year. Woolwich.

\section{THE APPLICATION OF THE THEORY OF EVOLUTION TO PATHOLOGY.}

\section{BY ALBERT GRESSWELL, M.B., B.A. OXON., \&C.}

THE rules and the reasonings of common sense admit of almost infinite expansion, and we find that the result of this extension of the universal law that every cause must have an effect, and inversely that every effect must have had a cause, could we but trace it, does, as a matter of fact, lead us to that belief in evolution which, having previously been recognised in every other department of human inquiry, has at length also been admitted to hold, even in the last strongholds of empiricism, the domains held by the monsters disease and death. For some time it has been held that the universe, together with all its multifarious contents, has gradually been developed from the simplest 